\title{
Budaya Masyarakat Dan Partisipasi Koperasi Terhadap Pembangunan Lingkungan Masyarakat Lokal di Kabupaten Pasuruan (Studi Kasus Pada Peternak Sapi Perah dan Koperasi Susu di Kabupaten Pasuruan)
}

\author{
Bambang Sutikno ${ }^{1)}$, Abdul Hakim ${ }^{2)}$ \\ ${ }^{1}$ Universitas Merdeka Pasuruan \\ ${ }^{2}$ Staf Pengajar Program Doktor Ilmu Lingkungan Universitas Brawijaya
}

\begin{abstract}
ABSTRAK
Budaya masyarakat yang terus dipertahankan secara turun temurun akan membentuk suatu perilaku yang saling mempengaruhi antara manusia dan lingkungannya. Penelitian ini bertujuan untuk mengetahui pengaruh budaya masyarakat terhadap pembangunan lingkungan masyarakat lokal dan partisipasi koperasi terhadap pembangunan lingkungan masyarakat lokal. Lokasi penelitian di koperasi kabupaten pasuruan dan pengambilan datanya menggunakan kuisioner. Jumlah sampel yang diambil sebanyak 70 sample dengan menggunakan random sampling. Analisi data menggunakan metode GSCA. Hasil penelitian menunjukkan variabel budaya masyarakat berpengaruh signifikan dengan pembangunan lingkungan masyarakat lokal, budaya masyarakat berpengaruh signifikan dengan pembangunan lingkungan masyarakat lokal, dan budaya masyarakat berpengaruh signifikan terhadap variabel partisipasi koperasi.
\end{abstract}

Keywords : budaya, pembangunan lingkungan, masyarakat lokal, koperasi.

\section{PENDAHULUAN}

Budaya masyarakat yang terus dipertahankan secara turun temurun akan membentu suatu perilaku yang saling mempengaruhi antara manusia dan lingkungannya. Interkasi manusia dengan lingkungannya mempengaruhi pandangan hidup, memahami sifat lingkungan, pengaruhnya terhadap dirinya dan reaksi lingkungan terhadap aktivitas hidupnya dan padangan hidup ini terakumulasi dalam perilaku masyarakat dan dikenal sebagai budaya masyarakat lokal. Pembangunan lingkungan ekonomi masyarakat lokal tidak terlepas dari kelembagaan sosial swadaya masyarakat yang langsung bersinggungan dengan kegiatan ekonomi produktifnya.

Budaya lokal adalah tata nilai atau perilaku hidup masyarakat lokal dalam berinterkasi dengan lingkungan tempatnya hidup secara arif. Kearifan lokal mengacu kepada nilai-nilai dalam masyarakat dan keseimbangan alam. Menurut Undang-undang no.32 tahun 2009 memberikan pengertian tentang kearifan lokal, yaitu nilai-nilai luhur yang berlaku dalam tata kehidupan masyarakat 
untuk antara lain melindungi dan mengelola lingkungan hidup secara lestari. Nilai-nilai dalam kearifan lokal menjadi modal utama dalam membangun ekonomi masyarakat tanpa merusak tatanan sosial dengan lingkungan alam.

Budaya ekonomi masyarakat merupakan sifat pandang manusia terhadap lingkungan akan terkait dengan kegiatan ekonominya dalam penyediaan kebutuhan hidup kesehariannya. Petani akan selalu memperhatikan lingkungan pertaniannya, begitu juga peternak akan memperhatikan lingkungannya agar ternak dapat hidup dengan layak dengan segala jenis pakan yang tersedia dalam lingkungan sebagai penyedia sumber pakan yang tak terputus. Begitu juga akan mengembangkan kegaiatan tersier dalam basis perternakan, sebagai pelaku ekonomi masyarakat lokal. Salah satu bentuk kegiatan tersier usaha perternakan sapi susu yang bersifat linier dengan adanya koperasi susu, sebagai wadah peternak menjual produksinya dengan harga yang stabil dan kontinyu, sebagai wujud oragnisasi ekonomi masyarakat lokal yang bersifat Identitas, yaitu anggota sebagai pemilik perusahaan dan anggota juga sebagai pengguna perusahaan, sifat ganda inilah yang cocok untuk komonitas masyarakat lokal dalam melakukan kegiatan ekonomi yang selaras dengan lingkungannya.

Sistem industri susu nasional di Indonesia sebagian besar merupakan kerjasama yang melibatkan peternak, koperasi dan IPS. Dalam sistem ini, susu segar didistribusikan secara vertikal dari peternak ke koperasi dan kemudian langsung didistribusikan ke IPS (Industri Pengolahan Susu). Koperasi susu berperan dalam memberikan layanan input produksi seperti penyediaan input pakan konsentrat, layanan kesehatan ternak, inseminasi buatan (IB), akses bantuan pinjaman modal dan tempat penjualan susu sebelum dijual ke IPS. Oleh karena itu, keberadaan koperasi susu sangat berperan penting sebagai wadah untuk meningkatkan kesejahteraan peternak dan meningkatkan pembangunan masyarakat lokal.

Produk susu di Indonesia merupakan struktur pasar monopsoni dimana $90 \%$ pangsa pasar dikuasai oleh industri pengolahan susu (IPS). Meskipun saat ini terdapat koperasi primer (Koperasi Unit Desa/KUD) dan koperasi sekunder (Gabungan Koperasi Susu Indonesia/GKSI), namun kenyataannya posisi tawar peternak masih rendah. Ketergantungan peternak terhadap IPS dalam memasarkan susu, mengakibatkan peternak berada pada posisi tawar 
(bargaining position) yang rendah. Tawaf et al. (2009) menyatakan bahwa harga susu di tingkat peternak lebih rendah dibandingkan dengan harga susu di tingkat konsumen. Hal ini menambah berbagai kendala yang dihadapi dalam industri susu nasional sebagaimana telah dilaporkan pada penelitian terdahulu oleh Priyono \& Zulfanita (2013) dan Krisna \& Manshur (2006). Salah satu simpul tata niaga produk susu adalah kelembagaan koperasi yang memiliki peran strategis dalam menopang perkembangan persusuan di Indonesia.

Koperasi dalam agribisnis sapi perah memiliki dua bentuk, yaitu koperasi monosifikasi yang hanya fokus pada usaha sapi perah dan koperasi diversifikasi yang membuka banyak usaha di samping usaha sapi perah (Yusdja 2005). Koperasi peternak pada umumnya bersifat diversifikasi, namun biaya untuk aktivitas dari usaha diversifikasi koperasi tersebut masih banyak yang berasal dari profit penjualan susu. Dampaknya, akan mempengaruhi sisa hasil usaha (SHU) yang diterima anggota. Oleh karena itu, penyelenggaraan ketatausahaan koperasi yang akuntabel merupakan salah satu bentuk usaha untuk menguatkan peran koperasi susu dalam kawasan sapi perah nasional. Menurut Asih et al. (2013) koperasi susu memiliki peran yang besar dalam pemasaran susu dan peningkatan produktivitas serta membantu akses permodalan peternak. M Kasim et al. (2011) strategi yang dapat dilakukan untuk pengembangan sapi perah antara lain dilakukan dengan meningkatkan populasi, pemberdayaan kredit usaha, optimalisasi lahan, penerapan teknologi, kemitraan usaha dan memperbaiki manajemen budidaya.

KUTT Suka Makmur yang ada di Kecamatan Grati Kabupaten Pasuruan dengan produksi 58 ton susu per hari, dengan jumlah peternak 4.000, kondisi topografi ada di dataran rendah $( \pm 10-$ $100 \mathrm{~m}$ dpl). Koperasi Susu sembada di Kecamatan Puspo Kabupaten Pasuruan dengan produksi susu 18 ton per hari, dengan jumlah peternak 7.425, kondisi topografi ada pada dataran sedang $( \pm 500$ - $700 \mathrm{~m}$ dpl). KPSP Setia Kawan Nongkojajar di kecamatan Tutur Kabupaten Pasuruan dengan produksi susu 71 ton per hari dengan jumlah peternak 8.125, topografi dataran tinggi ( \pm 900-1200 m dpl). .KUD Dadi Jaya yang ada di Kecamatan Purwodadi Kabupaten Pasuruan, dengan produksi 26 ton per hari, dan jumlah peternak 5.570, kondisi topografi berada ada pada ketinggian 600=800 m dpl. Produk olahan susu berupa minuman sebagai 
produk hom industri di daerah Nongkojajar.

Berdasarkan uraian di atas, maka perlu dilakukan penelitian lebih lanjut mengenai hubungan budaya masyarakat dan partisipasi koperasi terhadap pembangunan lingkungan masyarakat lokal di kabupaten pasuruan

\section{METODE PENELITIAN}

\subsection{Pengukuran}

\section{Variabel Budaya masyarakat}

Variabel ini menggunakan pengukuran skala likert 5 point. Indikatornya meliputi: partisipasi anggota, perawatan, dan pemanfaatan lingkungan

Variabel Partisipasi koperasi

Variabel ini menggunakan pengukuran skala likert 5 point. Indikatornya meliputi: kualitas pelayanan dan diversifikasi produk

Variabel Pembangunan lingkungan masyarakat lokal

Variabel ini menggunakan pengukuran skala likert 5 point. Indikatornya adalah ekonomi hijau

\subsection{Pengambilan data}

Metode pengambilan data dalam penelitian ini menggunakan pendekatan Slovin dalam Zulganef (2002) dengan jumlah data peternak sapi di 4 koperasi di daerah Kabupaten Pasuruan dengan jumlah sampel sebanyak 70 responden.

\subsection{Analisis Data}

Analisis data dalam penelitian ini menggunakan analisis GSCA. GSCA dapat digunakan untuk mendapatkan model struktural yang powerfull guna tujuan prediksi atau konfirmasi, selain itu GSCA juga powerfull untuk menguji model berbasis teori, atau dengan kata lain untuk mengkonfirmasi teori tentang hubungan antar variable yang terdapat di dalam model (Solimun, 2013).

\subsection{Hipotesis}

Hipotesis antar variabel dikaitkan dengan beberapa penelitian terdahulu dan hubungan antar variabel tersebut diperlihatkan pada Gambar 1.

Penurunan industri tradisional (seperti pedesaan industri desa, industri desa nelayan, dan suku aborigin industri), beberapa masyarakat pedesaan harus mengeksplorasi budaya mereka dalam memperkuat sumber daya ekonomi mereka untuk pengembangan pembangunan masyarakat (Lepp, 2007; Teh \& Cabanban, 2007; Wang et al., 2010). Peningkatan budaya masyarakat sangat berpengaruh pada tingkat pendapatan dan kesejahteraan untuk pembangunan lingkungan masyarakat selanjutnya (Anr'iquez, 2007). 


\section{Hipotesis 1 : budaya masyarakat berpengaruh terhadap pembangunan lingkungan masyarakat lokal}

Kondisi kompetitif untuk keterlibatan petani kecil di daerah dan nasional, serta peran yang dimainkan oleh lembaga pedesaan dalam rangka meningkatkan daya saing dan daya tawar (Hellin et al. 2006). Penciptaan koperasi pemasaran pertanian umumnya sebagai strategi untuk menghasilkan skala ekonomi dan memperkuat posisi tawar produsen skala kecil (Blokland dan Gouet, 2007). Interaksi sosial antara anggota koperasi atas dasar sosial norma, kepercayaan dan timbal balik, serta merupakan bagian jaringan internal dan eksternal (Ostrom 2004). 0,1 anggota koperasi berharap untuk mendapatkan keuntungan dari koordinasi keputusan produksi, berbagi akses ke input, disempurnakan kekuatan pasar dan kapasitas tawar lebih efektif (Di Falco et al., 2007). Anggota harus berkomitmen untuk memasarkan produk mereka dan membeli input mereka melalui koperasi (Thyfault, 1996). Komitmen ini secara intrinsik berdasarkan saling kepercayaan dan hubungan timbal balik antara anggota, sehingga kinerja koperasi tergantung pada kemampuan mereka untuk membangun dan menjaga kepercayaan, keyakinan dan komitmen antara anggota. Koperasi juga digambarkan sebagai suatu proses dimana anggota masyarakat berusaha menuju prioritas atau tujuan diri didirikan, biasanya didasarkan pada geografi umum, pengalaman umum, atau nilai-nilai umum (Cabaj, 2004).

\section{Hipotesis 2 : budaya masyarakat berpengaruh terhadap partisipasi koperasi}

Asih et al. (2013) koperasi susu memiliki peran yang besar dalam pemasaran susu dan peningkatan produktivitas serta membantu akses permodalan peternak. Bijman (2007) dan Valentinov (2004) merujuk pada faktor eksternal (misalnya langka adaptasi dengan tuntutan pasar) dan internal (yaitu perilaku oportunistik dari anggota dan konflik kepentingan) yang mempengaruhi organisasi ekonomi koperasi dan kohesi sosial. Bhuyan (2007) menegaskan bahwa faktor-faktor ini tidak terisolasi tetapi saling tergantung, menyiratkan bahwa koperasi perlu hati-hati menyeimbangkan kepentingan anggota dan persyaratan kewirausahaan.

Koperasi dapat menjadi strategi partisipatif yang efektif untuk bootstrap masyarakat berpenghasilan rendah ke 
dalam arus utama sosial-ekonomi (Majee dan Hoyt, 2011). koperasi dapat menjadi efektif strategi partisipatif untuk bootstrap masyarakat berpenghasilan rendah dalam mainstream sosialekonomi. Woolcock dan Narayan (2000) dan Nemon (2000), model sosial disesuaikan untuk menunjukkan potensi pengembangan usaha koperasi dan untuk mengontrol takdir sosial ekonomi masyarakat.

Koperasi membawa orang bersamasama untuk memenuhi kebutuhan bersama melalui operasi dari bisnis yang dikendalikan secara demokratis. Koperasi dapat melatih dan mendidik anggota
(Hoyt, 2004; Majee dan Hoyt, 2009) dan mempromosikan upaya kelompok untuk memenuhi kebutuhan individu dan masyarakat. Interaksi ini memungkinkan anggota untuk menggunakan mereka pengetahuan satu sama lain dan koperasi untuk terlibat dalam pemantauan rekan dalam perilaku bisnis mereka, sehingga secara lagnsung dapat memperkuat bisnis dan masyarakat (Majee \& Hoyt, 2009).

Hipotesis $3:$ partisipasi koperasi
berpengaruh terhadap
pembangunan lingkungan
masyarakat lokal

Hipotesis 3 : partisipasi koperasi berpengaruh terhadap masyarakat lokal

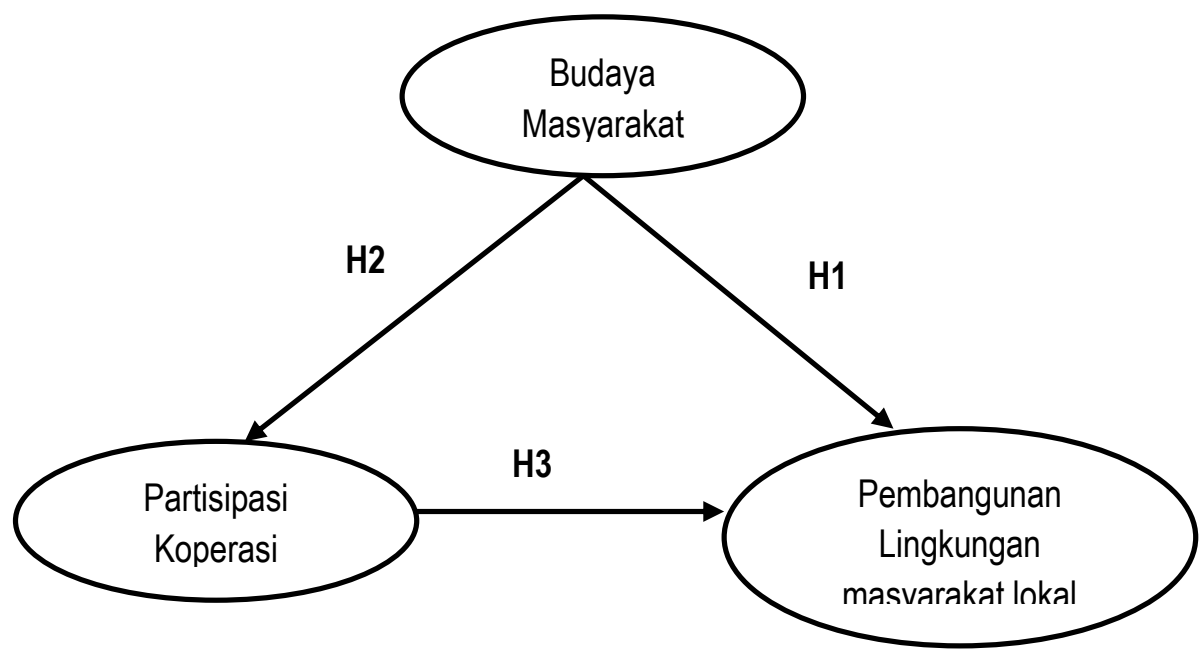

Gambar 1. Kerangka pemikiran penelitian

\section{HASIL DAN PEMBAHASAN}

3.1. Hubungan variabel budaya masyarakat dengan pembangunan lingkungan masyarakat lokal
Hasil analisis koefisen pengaruh langsung model estimate pada variabel budaya masyarakat dengan pembangunan lingkungan masyarakat lokal mempunyai hubungan positif dan signifikan dengan nilai 0,270 dengan SE sebesar 0,091. 
Hasil penelitian SE $>95 \%$, maka terdapat cukup bukti empiris untuk menerima hipotesis yang menyatakan bahwa variabel budaya masyarakat berpengaruh secara signifikan dengan pembangunan lingkungan masyarakat lokal. Koefisien pengaruh langsung bertdana positif $(0,270)$, hal ini mengindikasikan bahwa pengaruh keduanya searah. Artinya semakin tinggi masyarakat dalam mempertahankan budaya masyarakat, akan mengakibatkan peningkatan pada pembangunan lingkungan masyarakat.

\subsection{Hubungan budaya masyarakat} dengan partisipasi koperasi

Hasil analisis koefisen pengaruh langsung model estimate pada variabel budaya masyarakat dengan partisipasi koperasi adalah positif dan signifikan dengan nilai 0,225 dengan SE sebesar 0,078. Hasil penelitian SE> 95\%, maka terdapat cukup bukti empiris untuk menerima hipotesis yang menyatakan bahwa variabel budaya masyarakat berpengaruh signifikan terhadap variabel partisipasi koperasi. Koefisien pengaruh langsung bertanda positif $(0,225)$, hal ini mengindikasikan bahwa pengaruh keduanya searah. Artinya semakin tinggi masyarakat dalam mempertahankan budaya masyarakat, akan mengakibatkan meningkatknya partisipasi masyarakat dalam koperasi.

3.3. Hubungan variabel partisipasi koperasi dengan pembangunan lingkungan masyarakat lokal

Hasil analisis koefisen pengaruh langsung model estimate pada variabel budaya masyarakat berpengaruh secara signifikan dengan pembangunan lingkungan masyarakat lokal adalah positif dan signifikan dengan nilai 0,334 dengan SE sebesar 0,099. Hasil penelitian SE> 95\%, maka terdapat cukup bukti empiris untuk menerima hipotesis yang menyatakan bahwa variabel partisipasi koperasi berpengaruh signifikan terhadap variabel pembangunan lingkungan masyarakat lokal. Koefisien pengaruh langsung bertanda positif $(0,334)$, hal ini mengindikasikan bahwa pengaruh keduanya searah. Artinya semakin tinggi partispasi koperasi dalam meningkatkan kualitas layanan, akan mengakibatkan semakin meningkatkan pembangunan masyarakat lokal.

Model akhir yang terdapat dalam penelitian ini menempatkan variabel partisipasi koperasi sebagai driver peningkatan pembangunan lingkungan masyarakat lokal. Model akhir diperlihatkan pada Gambar 2.

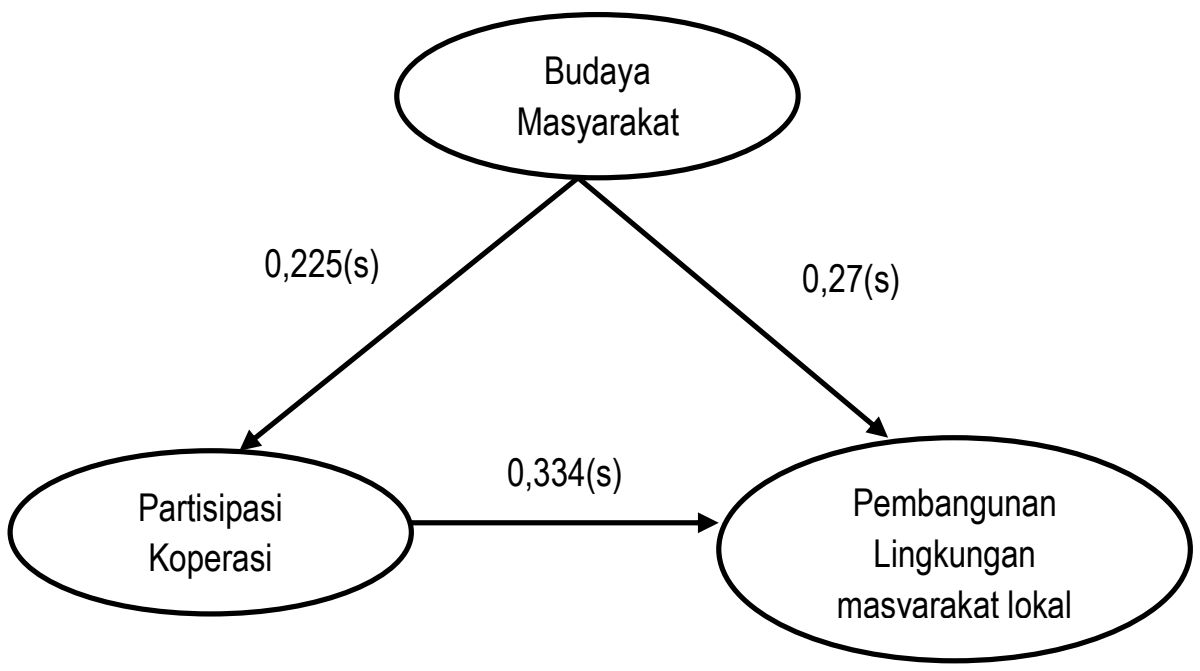

Gambar 2. Hasil analisis diagram jalur 


\section{KESIMPULAN DAN SARAN}

Berdasarkan hasil penelitian, analisis data dan pembahasan pada babbab sebelumnya, maka diperoleh kesimpulan sebagai berikut ;

1. variabel budaya masyarakat berpengaruh positif dan signifikan dengan pembangunan lingkungan masyarakat lokal.

2. variabel budaya masyarakat berpengaruh positif dan signifikan dengan pembangunan lingkungan masyarakat lokal.

3. variabel budaya masyarakat berpengaruh positif dan signifikan terhadap variabel partisipasi koperasi.

Saran pada penelitian ini adalah perlu dilakukan penelitian tentang ekonomi koperasi berbasis lingkungan dalam pembangunan masyarakat lokal peternak sapi perah (studi kasus pada koperasi peternakan, perkebunan, dan pertanian di kabupaten pasuruan)

\section{DAFTAR PUSTAKA}

Abdullah, I. 2009. Konstruksi dan rekonstruksi kebudayaan. Pustaka Pelajar. Yogyakarta.

Anonim, 2010. Partisipasi anggota koperasi. Deputi bidang pengembangan sumber daya manusia kementerian koperasi dan usaha kecil dan menengah republik indonesia

Anriques, G. 2007 Rural development and poverty reduction: is agriculture still the key? Agricultural Development Economics, 4(1), 5-46.

Asih, R., Murti, T.M., dan Haryadi, F.T. 2013. Dinamika pengembangan klaster industri persusuan di Kabupaten Semarang Jawa Tengah. Buletin Peternakan, 37, 59-66.

Bhuyans, 2007. The people factor in cooperatives: an analysis ofmembers attitudes and behavior. Canadian Journal of Agricultural Economics, 55, 275-298.

Bijman, J. 2007. How can cooperatives meet the challenges of agrifood supply chains?'In Ton G., Bijman J. and Oorthuizen J., eds, Producer Organizations and Market Chain, Wageningen: Wageningen Academic Publishers, pp. 91-116.

Bijman, J. and Hendrikse, G. 2003. Cooperatives in chains: institutional restructuring in the Dutch fruit and vegetables industry. Research Paper ERS-2003-089-ORG Rotterdam, Erasmus Research Institute of Management (ERIM).

Birchall, J. 2004. Cooperatives and the Millennium Development Goals. Retrieved from

http://www.communitywealth.org/_pdfs/articlespublications/outsideus/bookbirchall.pdf

Cabaj, M. 2004. CED and social economy in Canada: A people's history. Making Waves, 15, 13-120.

Di Falco, S., Smalem. and Perrings, C. 2008. The role of agricultural cooperatives in sustaining the wheat diversity and productivity: the case of southern Italy. Environmental \& Resource Economics, 39, 161-174.

Eta, Y. 2014. Rancangan UndangUndang Pengetahuan Tradisional 
Dan Ekspresi Budaya Tradisional Ditinjau dari Aspek Benefits Pasal 8J UNCED. Jurnal Arena Hukum, 7(3).

Hoyt, A. 2004. Consumer ownership in capitalist economies: Approaches of theory to consumer cooperation. In C. D. Merret \& Walzer, N. (Eds.), Cooperatives and lokal development: theory and applications for the 21st Century (pp. 265-286). New York, NY: M.E. Sharpe.

Ilham, N. dan Swastika, D.K.S.. 2000. Analisis Daya Saing Susu Segar Dalam Negeri Pasca Krisis Ekonomi dan Dampak Kebijakan Pemerintah Terhadap Usaha Peternakan Sapi Perah di Indonesia. Pusat Penelitian Sosial Ekonomi Pertanian. Bogor.

Lepp, A. 2007. Residents' attitudes towards tourism in Bigodi village, Uganda. Tourism Management, 28, $876 \mathrm{e} 885$.

Majee, W. and Hoyt, A. 2009. Building community trust through cooperatives: A case study of a worker-owned homecare cooperative. Journal of Community Practice, 17, 444-463

Majee, W. And Hoyt, A. 2011. Cooperatives and community development: A perspective on the use of cooperatives in development. Journal of Community Practice, 19(1), 48-61.

Nemon, H. 2000. Community economic development in distressed urban neighborhoods: A case study of the Philadelphia Empowerment Zone. Unpublished dissertation). Philadelphia, PA: University of Pennsylvania.
Nurmardiansyah, E. 2014. EcoPhilosophy dan Implikasinya Dalam Politik Hukum Lingkungan Di Indonesia. Journal. M. Lintas. Postgradeduate Student Parahyangan Catholic University. Bandung. Indonesia

Oktaviana, R.V. 2013. Strategi Pengembangan Primer Koperasi. Jurnal Administrasi Publik, 1(2), 257-264.

Ostrom, E. 2004. Understanding collective action. Collective action and property rights for sustainable development. Washington DC, International Food Policy Research Institute (IFPRI).

Pratikto, A. 2012. Pengaruh Budaya Terhadap Kinerja Perekonomian. Buletin Studi Ekonomi 17(2)

Priyono dan Priyanti, A 2015. Penguatan Kelembagaan Koperasi Susu melalui Pendekatan Pengembangan Kawasan Peternakan Nasional. Wartazoa, 25(2), 085-094.

Sairin, S. 2009. Strategi Kebudayaan dan Pengelolaannya. Makalah Seminar. Jakarta

Salim, E.. 2009. Pengarusutamaan Lingkungan Hidup dalam Pembangunan Nasional; Perspektif Ekonomi. Makalah Dialog Nasional. Jakarta.

Solimun, 2013. Penguatan Metodologi Penelitian Partial Least Square (PLS) \& Gerneral Structural Component Analysis (GSCA). Program Studi Statistika Fakultas MIPA. Universitas Brawijaya. Malang. 
Teh, L. and Cabanban, A.S. 2007. Planning for sustainable tourism in southern Pulau Banggi: an assessment of biophysical conditions and their implications for future tourism development. Journal of Environmental Management, 85(4), 999e1008.

Thyfault C. 1996. Developing new generation co-ops: getting started on the path to success. Rural Cooperatives, 63(4), 26-31.

Valentinov, V. 2004. Social capital and organisational performance: a theoretical perspective. Journal for Institutional Innovation, Development and Transition, 8, 2333.

Wang, H., Yang, Z., Chen, L., Yang, J. and Li, R. 2010. Minority community participation in tourism: a case of Kanas Tuva villages in Xinjiang, China. Tourism Management, 31(6), $759 \mathrm{e} 764$.

Woolcock, M. and Narayan, D. 2000. Social capital: Implications for development theory, research, and policy. The world bank research observer, 15(2), 225-249.

Yusdja, Y. 2005. Kebijakan ekonomi industri agribisnis sapi perah di Indonesia. Jurnal Analisis Kebijakan Pertanian, 3,1-11.

Zulganef. 2008. Metode penelitian Sosial dan Bisnis. Graha Ilmu. Yogyakarta 